\title{
Lingüística Quechua
}

\author{
Amancio Chávez Reyes \\ Departamento Académico de Lingüística
}

\section{Introducción}

La Lingüística Quechua es la denominación que justifica la preocupación focalizada de especialistas del área, propios y extraños, quienes desplegaron sendos estudios de la lengua a través de muy detenidas investigaciones en los últimos decenios. Sus autores hicieron del quechua un motivo de análisis y clasificación exhaustivos.

En la presente ocasión no nos referiremos â ninguna de las investigaciones efectuadas. Nos interesa acercar al lector u oyente, usuario del quechua, a tomar conciencia sobre la naturależa de tan vilipendiada lengua y la responsabilidad que deben asumir para defender de las garras del antiquechuismo.

\section{La escritura quechua}

\section{Biblioteca de Letras} "Jorge Puccinelli Converso"

El quechua es una lengua, que después de la conquista española empezó a ser escrita por los mismos conquistadores, adoptando, para tal efecto, el modelo alfabético español; no tomaron en cuenta los sonidos propios del quechua no obstante que los distinguían. Las diferencias fundamentales eran la presencia de la glotalizadas y aspiradas en quechua y la ausencia de los mismos en el castellano, además de la uvular y los grados de abertura vocálica ${ }^{1}$. No advirtieron ni los cambios automáticos ni las posibilidades grafémicas del que-

Quesada Castillo. Félix. 1997. Fonología y morfología del quechua de Cajamarca, CILA- UNMSM. Lima.

Chávez Reyes. Amancio. 1985. Gramática quechua, USMP.

Letras (Lima), 95-96: 161-170, 1998. 
chua ${ }^{2}$, implementaron su propio régimen escritural. Esta práctica continuó a lo largo del colonialismo y la república, con pequeñas modificaciones hasta 1975 en que se instituye un patrón fonológico para luego ser reajustado en 1983 en forma definitiva y con clara advertencia de las variantes fonológicas que debían tomarse en cuenta en las prácticas literales regionales. Claro que no es posible escribir el quechua, por lo menos actualmente, con un patrón ortográfico único. Sus variantes son formas radicalizadas que estarían a un paso de su autonomía.

El quechua registra dentro de su cuadro alfabético general 16 grafías consonánticas a las que se añaden las variantes fonológicas como: /tr/ (retrofleja) para el cajamarquino, las aspiradas /ph, qh, kh, th, chh/p, q, k, t, ch/ : glotalizadas para las consonantes oclusivas en el cusqueño, la africada $/ \mathrm{Cl}$ ' $t \mathrm{~s}$ ' para el ancashino, la velar fricativa / $\mathrm{x} /$ para el ayacuchano, la velar sonora /g/ para sanmartiniano, amazonense ycajamarquino?

En lo que respecta a las yocales se consideran sólo tres grafías en atención a la naturaleza trivocálica de esta lengua; en todas sus versiones deberían escribirse sólo con /i, u, a/ excepto el ancashino que cuenta además con tres vocales largas ${ }^{4}$. Sin embargo, en materia práctica casi en nada hemos superado el modelo colonial, actualmente se sigue escribiendo más o menos aficionadamente, y lo que es peor, es que lo hacen muy caprichosamente.

En cualquier lengua, si el alfäbeto es oficialmente reconocido es para que a partir de esto se oriénfer a fa practica uniforme, toda vez que deviene en la neutralización de las diferencias dialectales ${ }^{5}$. Mientras un grupo, cada vez creciente y respetable, orienta su concepción hacia el biculturalismo vía la aceptación escolar del quechua frente al castellano como posibilidad cognitiva no resulta admisible la práctica escritural regionalizada y/o fragmentada. La corriente linguo-pedagógica interculturalista tiene como objetivo la reivindicación de la lengua nativa en la expectativa de una sistematización lecto-escritural quechua-castellano.

A raíz de la oficialización del quechua, después de 1975, han surgido Academias Regionales de Quechua como filiales de la Academia General del

\footnotetext{
I Seminario sobre el alfabeto quechua. 1983, UNMSM-UNSCH

4 Parker, Gary, 1976. Gramaitica quechuta Ancash-Huaylas. I.E.P.

- Chávez Reyes. Amancio, 1980. Escritura r lenguas nasivas. Rev. San Martín No 1, USMP., Lima.
} 
Cusco. Sin embargo estas academias no están haciendo nada para uniformizar la escritura, asisten a un liberalismo lingüístico, cada quien escribe como buenamente lo puede hacer, sin preocuparle mínimamente el alfabeto, nadie se interesa en aprenderlo. El castellano lo tenemos que escribir de una sola manera, cual sea nuestro nivel cultural y/o social y cual fuere la variedad dialectal, es decir sea Castellano de América, sea de Europa. No estamos permitidos a la regionalización dialectal. Toda lengua, para los efectos de su grafización, depone las variantes dialectales y asume una única posibilidad escritural.

La escritura es vertebradora de la condición unitaria del sistema central formulado a partir de un cuadro fonológico. Esto no está ocurriendo en el quechua. Los aficionados que escriben confunden la ortografía con la del castellano. Así por ejemplo la $/ \mathrm{k} /$ y la $/ \mathrm{q} /$ suelen confundirlo con $/ \mathrm{c} /$, por ejemplo, / waktsa/ y /kaykan/ las escriben como /wactsa/ y /caycan/ o incluso como / huactsa/ y /caican/; la /q/ casi siempre confundida con la forma /qui/ /wawqi/ como /wawqui/, /wiqi/ como /wiqui/: la $/ \mathrm{h} / \mathrm{con} \mathrm{la} / \mathrm{j} / \mathrm{del}$ castellano: /hatun/ como /jatun/, /humpi/ como /jumpi/; la /w/ como thua/: / waaka/ como /huaca/ ${ }^{6}$. Estos son algunos de los más frecuentes errores, acaso voluntarios, en que incurren quienes la escriben.

Aprender la ortografía quechua resulta mucho menos difícil (o sea más fácil) que el castellano, es posible lograr su total dominio sin mucho esfuerzo, gracias a que sus grafemais nò presentan sithilitudes articulatorias como el castellano. Todas las grafías quechuas representan unidades articulatorias diferenciadas, no hay razón para confundirlas; sin embargo, pareciera que las dificultades encontradas en el castellano han creado reactivos sicolingüísticos que hacen que la gente se escude, más defensivamente, para considerar que la ortografía quechua es mucho más difícil que la del castellano, tal cual nos contestó una profesora de alfabetización, o es que se piensa que no importa cómo se escriba con tal que se pueda leer, tal como piensa este sector social de aficionados; la escritura no es un libertinaje que permite una actividad marginal. No es admisible escribir una lengua sin tener información ortográfica.

Es necesario advertir que una lengua no se escribe, ni por aproximación, ni por afición proyectiva, se escribe mediante el conocimiento de sus normas y reglas, que son consciente y volitivamente aprendidas. Para esto se aprende y se dan métodos. Acaso el alumno de Primaria y Secundaria no aprende la ortogra-

Rosales, Efraín 1994. Senrisas del Ande. Huaraz. 
fía a través de los modelos conocidos como "percentil", aunque no siempre logra su dominio? Lo que sucede es que los profesionales que escriben en quechua lo hacen por intuición, pues nunca la aprendieron porque tampoco existe quien les enseñe, el quechua no ha sido escolarizado ${ }^{7}$, y si no se logra su escolarización sólo el lingüista será el usuario correcto. Ni siquiera, los educadores o literatos podrán superar esta dificultad. La actual resistencia y dificultad evidencian que hay necesidad de hacer una actividad empírica permanente, la cual será posible sólo a través de su incursión formal en la Educación.

\section{Falacias en torno a la escritura quechua}

Cada lengua tiene sus modelos propios de escritura, no tiene que supeditarse ni ser semejante, y mucho menos calcar modelo alguno. Asimismo la escritura es modelo supralectal y no local ni grupal. Quien desea conocer y usar la escritura de una lengua, sea propia o extraña, tiene que aprender las normas diseñadas en esta lengua, por más caprichosas 0 arbitrarias que fueran. La posesión lecto-escritural es el resultado del aprendizaje, es la asunción superestructural, no es un resultado espontáneo como que lo es el modelo oral, sea o no nativo, resultado de simple adquisición. El aprendizaje y/o la enseñanza que debe efectuar el sujeto para ser lector o escribiente, indica que ni siquiera es un conocimientopasivo. Luego, el lenguaje, sea oral o escrito, es para el hombre una actividad permanente y forma el elemento constitutivo de su realización social ${ }^{8}$.

Ninguna lengua tiene dos modelos de escritura, todas aquellas que alcanzaran a ser escritas están basadas en un mismo y único modelo, no es posible dos fonologías, ni dos sistemas gráficos paralelos. Las posibles variantes dialectales, sean de carácter social o local, tienen exactamente los mismos recursos alfabéticos. La escritura tiene como justificación la representación unitaria de esas diferencias orales. Su objetivo principal, desde este punto de vista, es mantener la homogeneidad lecto-escritural. Lo que a nivel oral es permitida la diferencia, incluso individual, resultaría inconcebible en la escritura, en ésta las individualidades desaparecen. Sin embargo, el intento de intensificación de la escritura quechua como práctica social amplia encuentra aparentemente serios impases debido a las diferencias fonéticas entre los dialectos locales que

Escobar. Anna María, 1990. Los bilingües y el castellano en el Perú. 1.E.P

* Chávez Reyes, Amancio, 1995. Aspectos formales de la palabra castellana, UNMSM. 
por dinámica propia de toda lengua, el quechua presenta para la ingenuidad diferencias zonificables y por tanto como que fuera motivo para escribir en unas zonas distintas que otras como que si los alófonos presentaran rasgos distintivos como los fonemas. He ahí el caso, por ejemplo, del quechua ancashino que en sus siete posible variantes principales, que no pasan de ser un proceso evolutivo se tengan que escribir con grafías distintas. Esto, a nuestro criterio es adelantarse a los hechos. Nunca la lengua escrita se anticipa a la forma hablada. Esto es desconocer que la escritura se instituye sólo cuando las formas orales han consolidado sus variaciones.

Las variantes del quechua ancashino son: 1) Antonio Raymondi y alrededores, presenta la sonorización velarizada de /q/ como /g/: /nuqa/ como /nuga/ , /qam/ como/gam/, /qunqay/ como/gungay/, etc.; 2) la de Huari y cercanías, conservadora de las secuencias /ay,uy/aw/: /ayway, mikuy, wawqu/, etc.; 3) la de Pomabamba que presenta $/ \mathrm{h} / \mathrm{como}$ una etapa intermedia entre $/ \mathrm{s} / \mathrm{y} / \mathrm{y} /$, tal como /wahi/ que proviene de /wasi/ y termina como /wayi/ en que la /y/ es epentética; 4) la de Caraz que elide/a aspirada inicial temática: /ara, uk, atun, uti/ cuyos modelos iniciales fueron/sara/suk, satun y suti/, respectivamente; 5) la de Huaraz y cercanías que monoptongan las secuencias /ay, uy/aw/ derivando en las formas /ee, ii, oo/. Asípor ejemplo notamos en las formas/rikee/ por /rikay/ /wanii/ por/wanuy/, /wooki/ por/wawqi/; 6) la de Bolognesi que despalataliza la lateral /11/ como /l/: /lullu/ como /lulu/, /nuqalla/ como /nuqala/

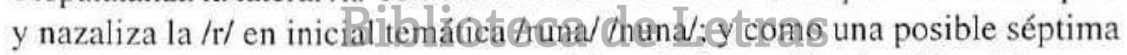
variante la de Carhuaz y Jungaypquectilizandoformadshuti y shipash/ en vez de /suti y sipas/ (tradicionales) y /huti y hipash/ formas innovadas?.

Las diferencias señaladas no pasan de un nivel dialectal, que en ningún caso tienen mérito para ser escritas de distintas maneras. Sin embargo existe un argumento, por demás sofismático, que viene internalizándose en la mente de incipientes aprendices de la lecto-escritura, éstos son argumentos falaces que tienen como escudo escribir las lenguas tal como lo hablan los pueblos y que según este sofisma el escribir de acuerdo a criterios históricos, para mantener la unidad macrolectal, es una idea conservadora y hasta reaccionaria y tal vez anticuada o ahistórica, que atenta contra la pretendida "modernización". La propuesta de escribir el quechua con perspectiva unitaria es la respuesta de un seguimiento histórico orientado a reivindicar y mantener la unidad lingüística del mundo andino. El supuesto criterio modernizante es una violentación escionista

Idem. 1997. Idioma y Cultura en la evolución de los Pueblos, Rev. Quevmy, INC. Huaraz. 
que apunta a la pérdida de las posibilidades de entendimiento entre los dialectos, es una escritura atomizante; lingüísticamente inconcebible y carente de todo criterio científico, acaso un funcionalismo gratuito y trasnochado. Nos preguntamos ¿por qué el castellano, tanto en América como en el resto del mundo, tiene un solo modelo de escritura? ¿Acaso no hay diferencias lectales profundas entre el castellano de América y el castellano de Europa? ¿Por qué el Inglés tiene la misma ortografía en Estados Unidos, Canadá y Gran Bretaña? ¿Por qué el Quechua tiene que escribirse con carácter localista? Esta es otra de las pretensiones de quienes pugnan por fragmentarnos para hacernos perder la posibilidad de una nueva unidad lingüística.

La Academia Regional de Ancash aún no ha tomado conciencia del daño y la complicidad en que puede incurrir, además de la responsabilidad histórica que le compete en su condición de entidad rectora. Es necesario emprender y desarrollar una política de unidad lingüística para contener la acelerada multilectalización que podría ser su extrema crisis antes de su total absorción por el castellano que, a su turno, avanza arrogante en su implacable persecusión antiquechua, valiéndose para ella fundamentalmente de la educación, que a decir verdad tiene su más fiel aliado en el profesorado nacional.

Es necesario advertir que el quechua de Ancash es uno y hay que mantener esa unidad. Quienes quieran enseñar no distorsionen la naturaleza de la lengua, y quienes quipran lessribicquedeaprendamsobre la base del criterio fonológico y no fonéticor El alfabeto diseñado y gficializado para el ancashino es uno y no varios. A traves de la práctica escritural debemos superar las diferencias locales ${ }^{10}$.

\section{El quechua y la literatura}

Una de las vertientes a través de las cuales se manifiesta el lenguaje es la literatura, una expresión intencionalizada y lograda mediante un lenguaje elaborado. Todo lenguaje literario está por encima de la mera espontaneidad lingüística y es predominantemente perfomativo que competitivo. El hombre utiliza el lenguaje con una serie de motivaciones individuales y sociales. Es así cómo el lenguaje cumple diferentes funciones en la interacción social que efectúa el hombre como posibilidades de competencia comunicativa individual.

\footnotetext{
i. Torero. Alfredo, 1996. "Los dialectos quechuas". Anales Cientificos de la U.N.A. Lima.
} 
De las varias funciones que cumplen las lenguas en la sociedad, la expresiva o emotiva y la estética o poética son las funciones que hacen mérito subrayar en el presente caso. Es de entender que todo hombre tiene entre sus necesidades instituir lingüísticamente sus sentimientos de nostalgia y alegría, sus glorias y penurias, como recursos catárticos que lo elevan a las más altas esferas de su humanidad, permitiéndole definirse en su verdadera esencia. Luego, toda lengua, al margen de su condición sociopolítica, presenta una posibilidad literaria para sus usuarios y no es una condición sinequanon de alguna lengua particular o dote exclusivo de algún privilegiado.

La literatura es una de las fuentes que con mayor incidencia enriquece connotativa y dennotativamente la lengua. Ella provee de nuevos giros semánticos a los lexemas que ya existen, crea nuevos términos con significados específicos relevándolas en todo caso y nunca las desemantiza. La literatura cumple una función de alta creatividad lingüística, no sólo porque incrementa el léxico con nuevas entradas sino también porque sus giros estilísticos contribuyen a lograr mayor sonoridad. La literatura es la manifestación externa del sentimiento subyacente del hombre.

Las diferentes formas de literatura, sean narrativas o poéticas, realistas o ficticias, épicas o líricas, todas inexorablemente todas, cumplen un objetivo común, expresan la belleza instituida mediante el lenguaje. Sus formas son constructos especialestguibaringerencen latseciedad pemp formas superiores en relación diglósica con el Jenguaje coloquial.por un lado y con los neologismos tecnolectales por otro lado. Se entiende que cada actividad desarrollada por el hombre genera un tipo de léxico, que puede considerarse como modo de producción. Que si la literatura es una actividad característica de quienes la producen y la cultivan permanentemente, entonces se deduce que existe un lenguaje como un lenguaje subliminal, construido en un estilo que lo personaliza a su autor. Las licencias de las que está premunido el autor le permiten crear figuras que lo elevan más allá de la simple gramaticalidad, a la vez que hacen del literato un cultor singular. El literato tiene mayor libertad lingüística que el gramático: pero asimismo tiene la mayor responsabilidad social de contribuir al mejoramiento cualitativo de la comunidad lingüística. Una lengua mejor cultivada será el reflejo de su cultivo literario. He ahí cómo los grandes clásicos que no inmortalizaron únicamente su nombre sino y sobre todo que hicieron del lenguaje huellas inmortales.

Entre el lenguaje y la literatura existe una profunda y estrecha relación. Es la misma que existe entre la causa y el efecto, al extremo de que no hay li- 
teratura sin lenguaje. Es más, podemos afirmar que la literatura es la fase superior del lenguaje, su forma superestructural, incluso en su modelo oral en el caso de las lenguas ágrafas, he ahí la mitonimia como organización lingüística especial. La literatura revierte sus logros no sólo en la producción lexical sino también en la sensibilización exquisita que hace del lenguaje más vibrante y musical. La literatura no puede ser sólo la forma alcanzada a partir de la escritura, todos los pueblos la crearon y la cultivaron tratando de explicar su origen a través de una literatura oral muchas veces incipiente. Evidentemente, la escritura relevó el lenguaje como posibilidad de un mejor desarrollo en todo orden de cosas. La literatura española no habría alcanzado su Edad de Oro sin grafización; no hubiera sido posible alcanzar el mítico encuentro entre el hombre y su divinidad para plasmarlos en las Sagrados Escrituras de todas las religiones.

Las diferentes actividades intelectivas tienen como correlato lingüístico el ensamblaje de un léxico especializado que lo consideramos como un metalenguaje natural a diferencia del simbólico como que son las fórmulas químicas y matemáticas. La literatura es una de estas actividades que crea, a través de cada autor y cada obra, un conjunto de términos, que de no ser nuevos toman nuevos campos semánticos $\sigma$ a veces lexicalizan frases como testimonios explicativos del fenómeno u objetó representado.

Veamos cómo figuranliastexpresiones-etcitaras de plumas", "ave

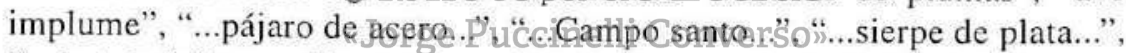
"...de tu balcón sus nidos a colgar...", "...la noche está estrellada...”, “...junco y capulí...", "...castillos de papel...", “...la vida es sueño...”, o los que podemos pensar en que el amor puede ser definido como "sueño en vigilia, primavera sin pétalos ni aroma, sinfonía sin eco, ternura incandescente, sentimiento desagarrado o musa sin poesía". La creación lingüística en literatura no debe entenderse, en definitiva, sólo como incremento cuantitativo sino también como el enriquecimiento semántico de los lexemos ya existentes.

\section{El quechua como posibilidad poética}

En razón de la caracterización general de las lenguas como justificación de la constante humana, es la producción de su acción. El quechua es, también, una lengua que con cierta facilidad puede contener y expresar los mil y un modo de actuar del hombre. Esto indica que el quechua también tiene un poten- 
cial poético y con la advertencia de que las palabras utilizadas en la poesía registran mayores posibilidades polisémicas que el castellano cotidiano. En esta última las palabras no pierden su valor referencial así ocurran en los contextos más variados. Lo que sí puede suceder es que los significantes pueden variar mientras que el significado se mantiene latentemente uniforme. En el quechua sucede lo opuesto, cambian los significados, pero los significantes pueden ser los mismos. Por ejemplo, /waktsa/ significa 'huérfano', pero también se usa con las connotaciones de 'pobre', 'desposeído', 'solitario'; / washki/ 'cordero', 'niño dócil', 'no uraño'; /mishki/ 'dulce, azúcar, caramelo, miel', 'comida agradable, buena comida (de calidad)', 'lo sabroso', 'comida bien preparada'.

La lengua quechua presenta una posibilidad exquisita para el quehacer poético, es una lengua que alcanza sonoridad en la combinación de palabras que se constituyen en cada verso. El uso de sufijos le da una flexibilidad que la hace más adecuada a los requerimientos sentimentales y permite construir metáforas, comparaciones y tođa clase de figuras literarias. Así por ejemplo / kuyay, mishki shunqu/ 'dulce eorazón amado - lata quri aqtsa/ 'larga cabellera dorada', /shumaq kuyay hapallayki kankif, 'eres la única musa', /shunqullaa wayllushunki/ 'mi corazón teadora'. En los siguientes versos podemos observar comparaciones y metáforas/qurinaw aqtsayki chipipin/, /shunquuta turwaatsin/ /wayta rikuq pukay pukay shimiki/ waray waray nuspatsiman/ 'tu cabellera brillante como el oro/ me embruja el corazón/ tus labios rojos como una flor me hacen delira: noche trasmocbes Letras

\section{"Jorge Puccinelli Converso"}

La poesía quechua también está en la capacidad de crear no sólo figuras sino términos, y a la vez que el estilo cada vez más refinado /kanankay yuraq raprachu qillqamuu/ qam pallar waqanaykipaq/ 'Te escribo en esta hoja blanca/ para que tu llores al leerlo'.

El quechua representa la inspiración idílica para el enamorado, un lirismo romántico para el poeta y una posibilidad literaria para el escritor. Pero, para que esta lengua tenga mejores condiciones estéticas requiere del cultivo estilístico permanente y de una reacción lexical amplia. Las lenguas alcanzan su desarrollo relevante sólo como resultado de una permanente actividad literaria. A decir verdad, el quechua presenta a la fecha una serie de limitaciones fundamentalmente lexicales debido a que ha subsistido en una condición sociocultural periférica, emplazada por el castellano a una función secundaria. Es necesario restituir y actualizar las palabras reemplazadas por el castellano y traducir más bien el castellano en quechua mediante la creación de nuevos términos que sean quechuas y no formas calcadas. 
Es tarea de actividades multiformes que realizan los hablantes para que la lengua, en este caso el quechua, pueda subsistir como lengua capaz de crear, traducir y expresar el mundo contemporáneo. Las lenguas subsisten sólo como registro de acciones y experiencias naturales que despliegan sus agentes. Si no se produce éste hecho sociocultural en forma constante la lengua tiende a congelarse en sus posibilidades de continuidad dinámica y puede eclipsar con el riesgo inminente de su absorción hispanizante. Esto suele experimentar el quechua, que ha sido reducida a un uso local e informal.

La práctica poética en quechua es escasa, no es una actividad permanente, ni siquiera los poetas quechuas presentan una inspiración frecuente. Es más, la poesía quechua tiene cultores únicamente en la variedad sureña y con especial incidencia la cusqueña, las demás variedades parecen auscultarse únicamente en el castellano.

La concepción errada que considera que la forma cusqueña es la única lengua quechua verdadera relegando a las otras a un plano sólo dialectal parece haber subestimado a los usuarios como que no tuyieran una posibilidad poética. Es más, el contacto con el castellano ha signifieado la incursión masiva de los préstamos. Muchas palabras quechuas han sido sustituidas por las del castellano. Luego, esto se traduce en serias dificultades lexicales para hacer poesía; en cambio la forma cusqueña siempre ha pretendido mantener la pureza lexical además de que los poetas grean puevos términos para dar respuesta a sus inspiraciones.

\section{"Jorge Puccinelli Converso»}

\section{Conclusiones}

a. Quienes usamos el Quechua, en cualquiera de sus variedades, debemos asumir un doble compromiso con la lengua, porque ella representa nuestro ancestro socio cultural:

b. Escribir con un solo modelo ortográfico para mantener su unidad. Para esto se recomienda tener en cuenta las formas conservadoras que existen actualmente.

c. Relevar el Quechua a la literatura escrita para mantenerla vigente en sus posibilidades de desarrollo constante. 